\title{
DVR using Diode Clamped Multilevel Inverter with Phase Disposition Pulse Width Modulation Technique
}

\author{
V. Priya \\ PG Scholar, EEE Department, \\ SNS College of Engineering, \\ Coimbatore, India.
}

\author{
M. Maheswari \\ Associate Professor, EEE Department, \\ SNS College of Engineering, \\ Coimbatore, India.
}

\author{
R. Saranya \\ PG Scholar, EEE Department, \\ SNS College of Engineering, \\ Coimbatore, India.
}

\begin{abstract}
Power problems affecting today's technological equipments are often generated locally within a facility from many number of situations. The major problem of the power quality is voltage sag. In this paper, Dynamic Voltage Restorer (DVR) is implemented using diode clamped multilevel inverter with phase disposition pulse width modulation. In the existing system, the various hysteresis modulation approaches are available in multilevel inverters. Since the number of levels of the inverter is increased, a new technique called phase disposition PWM is proposed. In this technique the carrier amplitude is increased and compared with the original signal to generate the pulses. The voltage sag problem can be rectified by DVR with corresponding time period. The main aim is to improve the power quality of the load voltage. The simulation is carried out using MATLAB/SIMULINK software and the results are presented and discussed in this paper.
\end{abstract}

\section{Keywords:}

Dynamic Voltage Restorer (DVR), Phase Disposition PWM, Diode Clamped Multilevel Inverter (DCMLI).

\section{INTRODUCTION}

Power quality is certainly a major concern in the present era; it becomes especially important with the introduction of sophisticated devices, whose performance is very sensitive to the quality of power supply. Modern industrial processes are based on a large number of electronic devices such as programmable logic controllers and adjustable speed drives. The electronic devices are very sensitive to disturbances and thus industrial loads become less tolerant to power quality problems such as voltage dips, voltage swells, and harmonics.

Voltage sags can occur at any instant of time, with amplitudes ranging from $10-90 \%$ and a duration lasting for half a cycle to one minute. Voltage swell, on the other hand, is defined as an increase in rms voltage or current at the power frequency for durations from 0.5 cycle to 1 minute, typical magnitudes are between 1.1 and $1.8 \mathrm{pu}$. Voltage swells are not as important as voltage sags because they are less common in distribution systems. Voltage sags and swell can cause sensitive equipment to fail, or shutdown, as well as creates a large current unbalance that could blow fuses or trip breakers. These effects can be very expensive for the customer, ranging from minor quality variations to production downtime and equipment damage.

Series connected custom power devices are used to prevent sensitive load from sag interruption in the source side. Static Synchronous Series Compensator (SSSC) and Dynamic Voltage Restorer (DVR) both are presently used for series voltage sag compensation. Operating principle and functioning of these devices differ significantly as the SSSC injects a balance voltage in series whereas the DVR compensates the unbalance in supply voltage of different phases. The DVR supplies the active power with the help of DC energy storage and required reactive power is generated internally without any means of DC storage. The DVR can compensate voltage at both transmission and distribution sides [3]. Usually a DVR is installed on a critical load feeder. During the normal operating condition (without sag condition) DVR operates in a low loss standby mode. During this condition the DVR is said to be in steady state. When a disturbance occurs (abnormal condition) and supply voltage deviates from the nominal value, DVR supplies voltage for compensation of sag and is said to be in transient state [2].

\section{DYNAMIC VOLTAGE RESTORER}

The Dynamic Voltage Restorer (DVR) is fast, flexible and efficient solution to voltage sag problem [2]. It is a powerful electronic based device that provides three phase controllable voltage source, whose voltage vector (magnitude and angle) adds to the source voltage during sag event, to restore the load voltage to pre-sag conditions [13]. It is designed for protecting the whole plant with loads in the range of some MVA. It can restore the load voltage within a few milliseconds. 


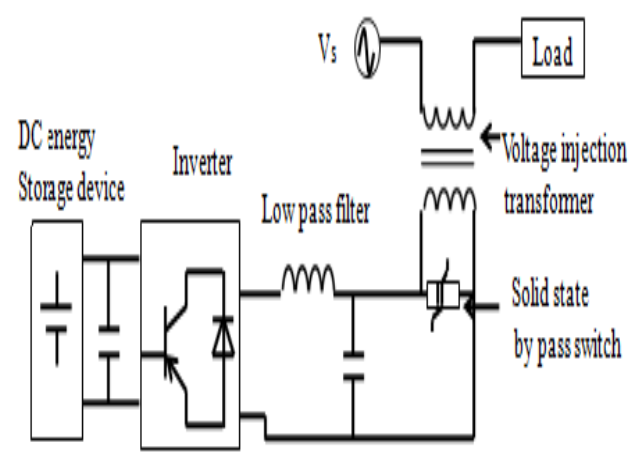

Figure 1 Schematic diagram of DVR

Figure 1 represents the schematic diagram of DVR. It contains the basic configuration and components as follows:

\subsection{DVR BASIC CONFIGURATION AND COMPONENTS}

During voltage sags, the DVR injects a voltage to restore the load supply voltages. The DVR needs a source of this energy. Two types of system are considered, one using stored energy to supply the delivered power and the other having no internal energy storage, where energy is taken from the incoming supply through a shunt converter.

\subsubsection{Inverter Circuit}

The Voltage Source Inverter (VSI) or simply the inverter, converts the DC voltage of the energy storage unit (or the DC link) to a controllable three phase AC voltage [13]. The inverter switches are normally fired using a sinusoidal Pulse Width Modulation (PWM) scheme. Since the vast majority of voltage sags seen on utility systems are unbalanced, the VSI will often operate with unbalanced switching functions for the three phases, and must therefore treat each phase independently. Moreover, a sag on one phase may result in a swell on another phase, so the VSI must be capable of handling both sags and swells simultaneously [3]. Another topology of the DVR is the use of the multi - inverter system in the cascade. This method gets rid of the injection transformer used in the basic configuration of the DVR. This arrangement is often called a transformer-less or multilevel or a cascade inverter DVR.

\subsubsection{Filtering Unit}

The nonlinear characteristics of semiconductor devices cause distorted waveforms associated with high frequency harmonics at the inverter output. To overcome this problem and provide high quality energy supply, a harmonic filtering unit is used. These filters can be placed either on the inverter side or on the line side.

\subsubsection{Series Injection Transformer}

Three single-phase injection transformers are used to inject the deficit voltage to the system at the load buses. To integrate the injection transformer correctly into the DVR, the MVA rating, the primary winding voltage and current ratings, the turn-ratio and the short-circuit impedance values of transformers are required. The existence of the transformers allow for the design of the DVR in a lower voltage level, depending upon the stepping up ratio.

\section{MULTILEVEL INVERTERS}

Multilevel inverter technology has emerged recently as a very important alternative in the area of high-power medium-voltage energy control [11]. The main concept of this inverter is to use diodes to limit the power devices voltage stress. A $\mathrm{n}$ level inverter needs $(n-1)$ voltage sources, $2(n-1)$ switching devices and $(n-1)(n-2)$ diodes. This paper presents the most important topologies like diode-clamped inverter (neutral-point clamped) with separate DC sources [6]. The term multilevel starts with the three-level inverter. By increasing the number of levels in the inverter, the output voltages have more steps generating a staircase waveform, which has a reduced harmonic distortion [1]. However, a high number of levels increases the control complexity and introduces voltage imbalance problems. [9]. In a five level diode clamped inverter consists of 8 switches, 12 diodes and 4 capacitors.

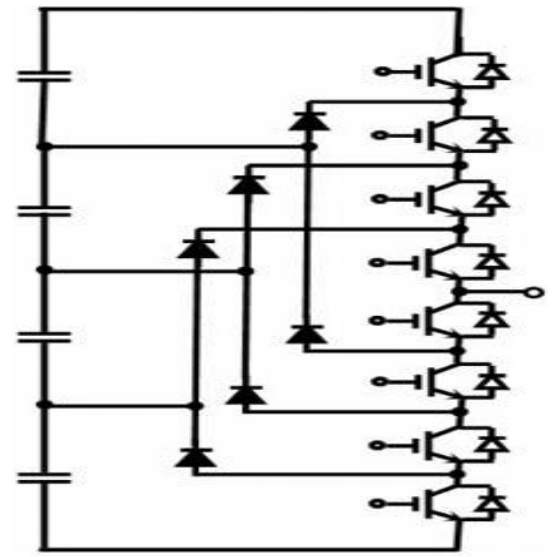

Figure 2 Five level diode clamped inverter

A 5-level diode clamped multilevel inverter is shown in Figure.2. For example to have Vdc/2 in the output, switches $\mathrm{S} 1$ to $\mathrm{S} 4$ should conduct at the same time. For each voltage level four switches should conduct. As it can be seen, the maximum output voltage at the output is half of the DC source [8]. It is a drawback of the diode clamped multilevel inverter. This problem can be solved by using a two times voltage source or cascading two diodes clamped multilevel inverters. We have seen DVR using diode clamped fifteen level multilevel inverter with phase disposition multicarrier PWM technique.

\section{CONTROL TECHNIQUE}

\subsection{Phase Disposition PWM (PDPWM)}

The rules for phase disposition method for a multilevel inverter are four carrier waveforms in phase are arranged [12]. The converter is switched to $+\mathrm{Vdc} / 2$ when the sine wave is greater than both upper carrier. The converter is switched to $+\mathrm{Vdc} / 4$ when the sine wave is greater than the first upper carrier. The converter is switched to zero when a sine wave is lower than upper carrier but higher than the lower carrier. The converter is switched to $-\mathrm{Vdc} / 4$ when the sine wave is less than first lower carrier. The converter is 
switched to $-\mathrm{Vdc} / 2$ when the sine wave is less than both lower carriers. The following formula is applicable to sub harmonic PWM strategy i.e. PD, POD and APOD.

The frequency modulation index

$$
\mathrm{mf}=\mathrm{fc} / \mathrm{fm}
$$

The Amplitude modulation index

$$
\mathrm{ma}=2 \mathrm{Am} /(\mathrm{m}-1) \mathrm{Ac}
$$

where $\mathrm{fc}-$ Frequency of the carrier signal $\mathrm{fm}$ - Frequency of the reference signal Am-Amplitude of the reference signal Ac - Amplitude of the carrier signal m- Number of levels.

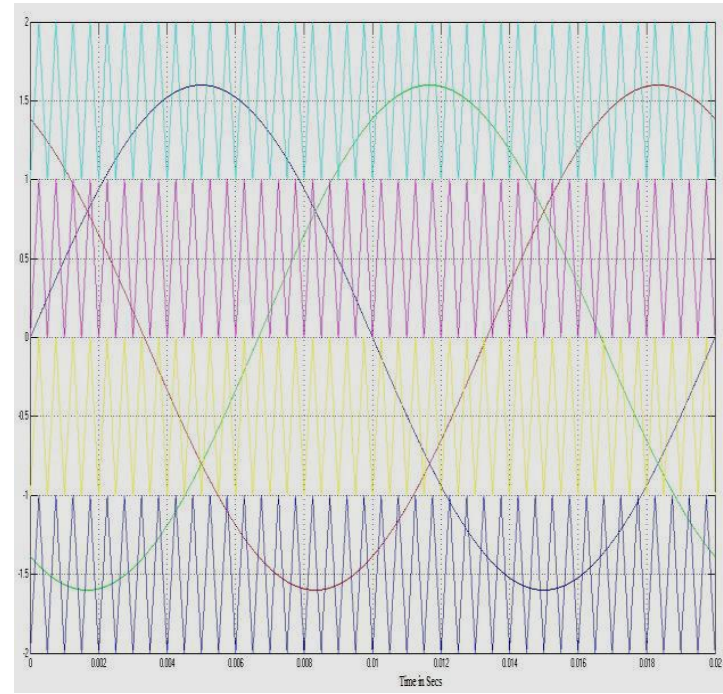

Figure 3 Carrier arrangement for PDPWM strategy

Carrier arrangement for PDPWM strategy is shown in figure. 3. PDPWM technique consists of all four carrier waveforms are in phase [14]. In this technique the carrier amplitude is increased and compared to the original signal to generate the pulses. The voltage sags problem can be rectified by DVR with corresponding time period [7].

\section{DVR USING DIODE CLAMPED MULTILEVEL INVERTERS}

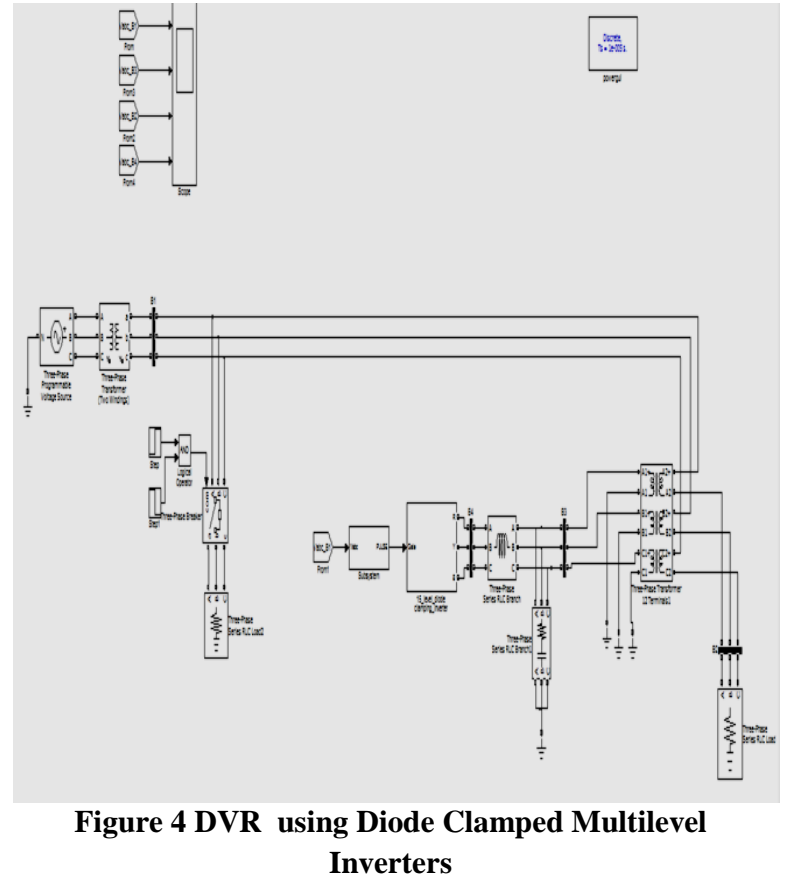

DVR using the Diode Clamped Multilevel Inverter is shown in figure 4. The main aim of this project is to mitigate the voltage sag and improve the power quality. One such reliable customer power device used to address the voltage sag, swell problem is the Dynamic Voltage Restorer [4]. In this circuit diagram, the three phase source supplies the source voltage (grid voltage) which can be measured by the voltage measurement block which is placed beside it. A breaker circuit which is placed in between the source and load induces the voltage sag. Two step signals are used to set the intermediate values at which voltage sag occurs. During that particular interval of time (to which the step signals are set) a pulse is given to breaker circuit which is initially at open condition. As soon as the pulse is received, the breaker circuit closes thereby allowing the supply of voltage to the heavy load to which it is connected. Thus the voltage supply to the load drops (decreases) at this particular interval.This voltage drop is known as voltage sag. The simulated result of the above schematic diagram is shown below, the intermediate values at which sag occurs is set from $0.1 \mathrm{Sec}$ to $0.3 \mathrm{Sec}$. It contains B1 which is used to produce the input sag voltage. B2 represents the output area (compensate voltage). B3 denotes the injected voltage. B4 represents the multilevel inverter part. After the sag is produced, Vabc is the feedback input voltage given to the subsystem block. In this block the corresponding sine pulse is to be generated. $\mathrm{Vabc}$ is to be splitted into individuals $\mathrm{Va}, \mathrm{Vb}, \mathrm{Vc}$ subsystem, the carrier signal is to be produced. It contains the lookup table in which the carrier amplitude is to be increased the corresponding carrier pulse is to be generated. This is the concept of the phase disposition PWM and it is compared to the original signal [10]. $\mathrm{Va}, \mathrm{Vb}, \mathrm{Vc}$ are all combined to produce the corresponding gate pulse. That gate pulse is given the input of the diode clamped multilevel inverter. The corresponding output voltage is to be produced. Hence the load voltage is to same as grid voltage without any power quality disturbances i.e., The voltage sags/swell is compensated. 


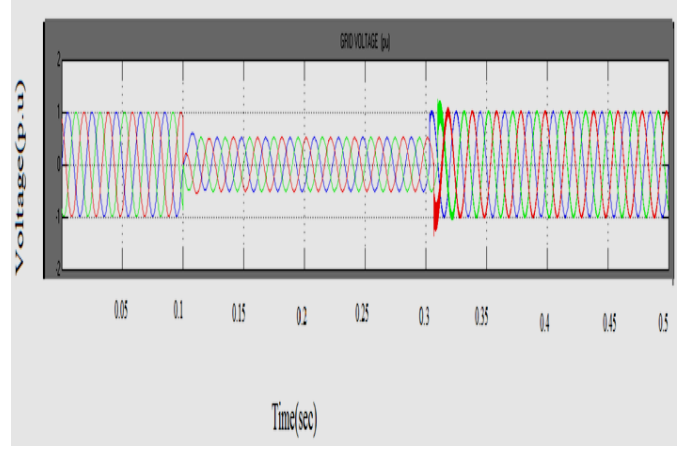

Figure 5 Waveform of grid voltage

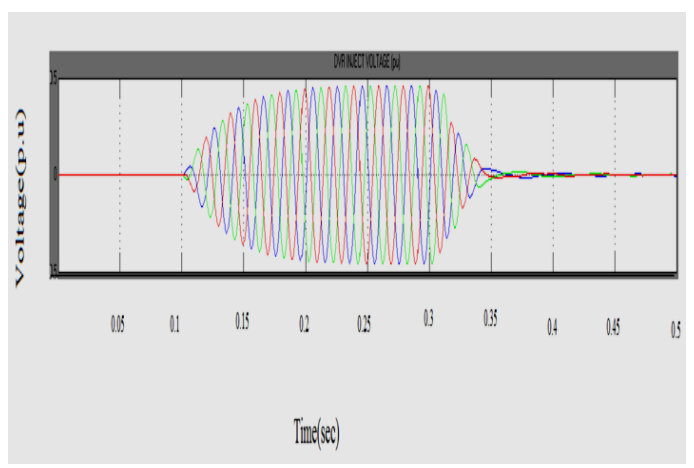

Figure 6 Waveforms of DVR injected voltage

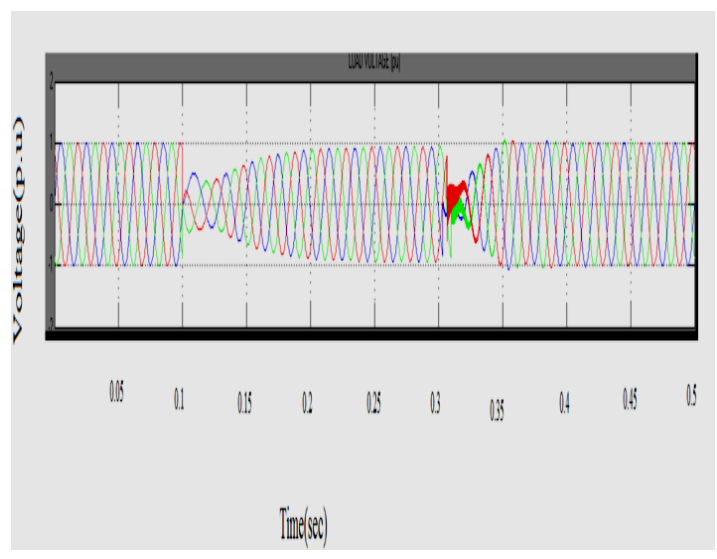

Figure 7 Waveforms of compensated load voltage

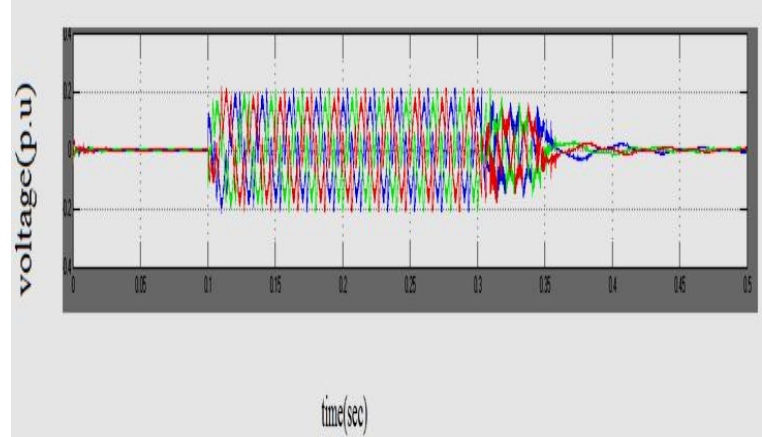

Figure 8 Output waveforms of fifteen level inverter

In Figure. 5, it represents the waveform of grid voltage. The voltage sag occurs between $0.1 \mathrm{Sec}$ to $0.3 \mathrm{Sec}$. The DVR voltage is injected as shown in Figure.6. The corresponding carrier pulse is generate. The waveform of compensated load voltage is as shown in Figure. 7. The main aim is to improve the power quality. The overall output waveform of diode clamped multilevel inverter is shown in figure. 8 . The main aim is to mitigate the voltage sag using dynamic voltage restorer with phase disposition pulse width modulation technique [5].

\section{CONCLUSIONS AND FUTURE WORK}

In this paper, the implementation of DVR using diode clamped multilevel inverter with phase disposition pulse width modulation. Voltage sag problem can be rectified by Dynamic Voltage Restorer. The main function of the DVR is to monitor the load voltage waveform constantly and if any sag or surge occurs, the balance voltage is injected to the load voltage. The PD PWM technique is used, the carrier amplitude is increased and compared with the original signal to generate the carrier pulse. The main aim is to improve the power quality and to compensate the voltage sag.In future, the phase opposition disposition pwm and alternative phase opposition disposition pwm methods can be used to improve the power quality.

\section{REFERENCES}

[1] Anshuman Shukla, Arindam Ghosh and Avinash Joshi, "Hysteresis Modulation of Multilevel Inverters" IEEE Transaction on power electronics, Vol.26, No.5, May 2011.

[2] AgileswariK. Ramasamy, Rengan Krishnan Iyer and Dr. R. N. Mukerjee, "Dynamic Voltage Restorer for voltage sag compensation,'IEEE PEDS, 2005.

[3] C. Benachaiba and B. Ferdi, "Power quality improvement using a DVR," American Journal of Applied Sciences 6 3): 396-400,2009.

[4] Chris Fitzer and Mike Barnes, "Voltage Sag Detection Technique for a Dynamic Voltage Restorer," IEEE Trans. Vol.40, No.1, Jan. 2004.

[5] E. W. Gunther and H. Mehta, "A Survey of distribution system power quality," IEEE Trans. Power Del., Vol.10, No.1, pp. 322-329, Jan.1995. 
[6] Pedro RonceroSanchez, "Dynamic Voltage Restorer Based on Flying Capacitor Multilevel Converters Operated by Repetitive Control," IEEE Trans. Power Delivery, Vol.24, No 2, April 2009.

[7] SNV Ganesh, Dr. k. Ramesh Reddy and Dr. B. V. Sanker Ram,"Different Control Strategies for Power Quality Improvement Using Dynamic Voltage Restorer", IEEE Students Technology Symposium 1416 Jan. 2011.

[8] A. Shukla, A. Ghosh and A. Joshi, "Control schemes for DC capacitor voltage equalization in diode-clamped multilevel inverter based STATCOM", IEEE Trans. Power Del., Vol. 23, No. 2, pp. 1139-1149, Apr. 2008.

[9] A. Shukla, A. Ghosh and A. Joshi, "Improved multilevel hysteresis current regulation and capacitor voltage balancing schemes for flying capacitor multilevel inverter", IEEE Trans. Power Electron., Vol. 23, No. 2 , pp. 518-529, Mar. 2008.

[10] H. Kanaan, K. A. Haddad, R. Chaffai, L. Duguay and F. Fnaiech, "A comparative study of hysteresis and PWM control techniques applied to an injection-current-based three-phase rectifier", in Proc. Can. Conf. Electr. Comp. Eng., vol. 2, 2001, pp. 785-792.

[11] J. Rodriguez, L. G. Franquelo, S. Kouro, J. I. Leon, R. C. Portillo, M. A.M. Prats and M. A. Perez, "Multilevel inverters: An enabling technology for high-power applications", Proc. IEEE, Vol. 97, No. 11, pp. 17861817, Nov. 2009.

[12] M. P. Kazmierkowski and L. Malesani, "Current control techniques for three-phase voltage-source PWM converters: A survey", IEEE Trans. IND. Electron., Vol. 45, No. 5, pp. 691-703, Oct. 1998.

[13] P. C. Loh, G. H. Bode and P. C. Tan, "Modular hysteresis current control of hybrid multilevel inverters," in Proc. IEE Electric. Power Appl., Vol.152, Jan. 2005, pp. 1-8.

[14] S. Leela and S. S. Dash ,"Control of three level inverter based dynamic voltage restorer", Journal of theoretical and applied information technology. 